\title{
Modification of mechanical and thermal properties of fly ash-based geopolymer by the incorporation of steel slag
}

\author{
I. Niklioć ${ }^{\text {a,* }}$, S. Marković ${ }^{b}$, I. Janković - Častvan ${ }^{c}$, V.V. Radmilović ${ }^{d}$, Lj. Karanović $^{\mathrm{e}}$, \\ Biljana Babić ${ }^{\mathrm{f}}$, V.R. Radmilovićc ${ }^{\mathrm{c} g}$ \\ a University of Montenegro, Faculty of Metallurgy and Technology, Džordža Vašingtona bb, 81000 Podgorica, Montenegro \\ ${ }^{\mathrm{b}}$ Institute of Technical Sciences of the Serbian Academy of Sciences and Arts, Knez Mihailova 35/IV, Belgrade 11000, Serbia

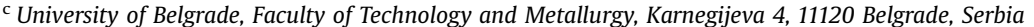 \\ ${ }^{\mathrm{d}}$ Innovation center, University of Belgrade, Faculty of Technology and Metallurgy, Karnegijeva 4, 11120 Belgrade, Serbia \\ e University of Belgrade, Faculty of Mining and Geology, Laboratory of Crystallography, Đušina 7, 11000 Belgrade, Serbia \\ ${ }^{\mathrm{f}}$ University of Belgrade, Vinča Institute of Nuclear Sciences, P.O. Box 522, 1100 Belgrade, Serbia \\ ${ }^{\mathrm{g}}$ Serbian Academy of Sciences and Arts, Knez Mihailova 35, Belgrade, Serbia
}

\section{A R T I C L E I N F O}

Article history:

Received 24 November 2015

Received in revised form

18 March 2016

Accepted 16 April 2016

Available online 19 April 2016

Keywords:

Geopolymers

Porous materials

Thermal properties

Steel slag

Fly ash

\begin{abstract}
A B S T R A C T
Geopolymeric binders (GB) were produced using fly ash (FA) and electric arc furnace slag (EAFS). The slag has been added in the range of $0-40 \%$. The effects of slag content on the strength, microstructure and thermal resistance were evaluated. It was found that the amount of EAFS up to $30 \%$ positively affects the strength evolution of GB. The main reaction product of FA/EAFS blends was amorphous $\mathrm{N}-(\mathrm{C})-\mathrm{A}-\mathrm{S}-\mathrm{H}$ gel along with geopolymer-type gel (N-A-S-H). Thermal resistance of GB was considered from the standpoint of their mechanical and dimensional stability after heating in the temperature interval of 600 $800{ }^{\circ} \mathrm{C}$. The changes in mechanical and thermal properties of GB after heating are attributed to the changes in their structure. The results have shown that EAFS negatively affects the thermal resistance of $\mathrm{GB}$ above $600{ }^{\circ} \mathrm{C}$ due to the phase transition and morphological transformation of the amorphous gel phase.
\end{abstract}

(c) 2016 Elsevier B.V. All rights reserved.

\section{Introduction}

The role of FA in the production of GB is a novel way for utilizing by-products from the construction industry, especially for its environmental benefits. In general, geopolymers are produced by the alkali activation of aluminosilicate materials (fly ash and metakaolin) with a highly alkaline activator, which leads to the formation of an amorphous sodium aluminosilicate ( $\mathrm{N}-\mathrm{A}-\mathrm{S}-\mathrm{H})$ gel as a reaction product [1]. Alkali activation of slag results in a different reaction product, calcium alumino silica $(\mathrm{C}-\mathrm{A}-\mathrm{S}-\mathrm{H})$ gel [2]. Properties of both, fresh and hardened FA-based GB can be improved by the addition of Ca-rich materials like blast furnace slag, which leads to the formation of an additional C-A-S-H gel, as a result of slag hydration during the alkali activation process [3]. The addition of slag to the FA affects the amount of the reaction product as well as the silicate structure, leading to a highly polymerized structure [4] and thus improving the properties of GB [5].

The aim of this research was to investigate the influence of EAFS addition on the strength and thermal resistance of FA-based

\footnotetext{
* Corresponding author.

E-mail address: irena@ac.me (I. Niklioć).
}

GB. Thermal stability of blended binders containing FA and EAFS was through their mechanical and dimensional stability at elevated temperatures.

\section{Experiment}

The FA and EAFS, with the average grain size $\left(d_{50}\right) 82 \mu \mathrm{m}$ and $24 \mu \mathrm{m}$, respectively, were used for the synthesis of GB. Total pore volume and BET (Brunauer-Emmett-Teller) surface area of fly ash were $0.042 \mathrm{~g} / \mathrm{cm}^{3}$ and $36 \mathrm{~m}^{2} / \mathrm{g}$ while for slag these values were $0.005 \mathrm{~g} / \mathrm{cm}^{3}$ and $4 \mathrm{~m}^{2} / \mathrm{g}$, respectively. The main oxide constituents of FA were $55.62 \% \mathrm{SiO}_{2}, 20.11 \% \mathrm{Al}_{2} \mathrm{O}_{3}, 9.44 \% \mathrm{CaO}, 5.78 \% \mathrm{Fe}_{2} \mathrm{O}_{3}$, $4.32 \% \mathrm{~K}_{2} \mathrm{O}, 1.9 \% \mathrm{MgO}$, while EAFS comprises of $46.5 \% \mathrm{CaO}, 23.5 \%$ $\mathrm{FeO}, 12.2 \% \mathrm{SiO}_{2}, 6.5 \% \mathrm{MgO}$, and $7.24 \% \mathrm{Al}_{2} \mathrm{O}_{3}$. Four binary mixtures of FA and EAFS (FA/EAFS with mass ratio of 100/0, 80/20, 70/30 and 60/40; denoted as F/S-100/0, F/S-80/20, F/S-70/30, F/S-60/40, respectively) were prepared by mixing known masses of FA or FA/ EAFS mixtures with an alkali activator at a solid to a liquid to solid ratio of 0.77 . The alkali activator was prepared by mixing sodium water glass $\left(\mathrm{SiO}_{2} / \mathrm{Na}_{2} \mathrm{O}=3.2\right)$ with $10 \mathrm{M} \mathrm{NaOH}$ solution in a mass ratio of 1.5 . The $\mathrm{SiO}_{2} / \mathrm{Na}_{2} \mathrm{O}$ ratio of final alkali solution was 1.23 . 
Geopolymeric paste was cast in a cylindrical mold, cured for $48 \mathrm{~h}$ at $65{ }^{\circ} \mathrm{C}$, removed from the mold and left to rest for an additional 4 weeks at ambient temperature. For the thermal treatment the samples were heated to 400,600 and $800{ }^{\circ} \mathrm{C}$ for period of $60 \mathrm{~min}$

The normal consistency of the geopolymer paste was determined by the Vicat apparatus. The GB samples were tested for compressive strength. Measurements of total pore volume and pore size distribution were carried out using $\mathrm{N}_{2}$ adsorption/desorption isotherms. Microstructural investigations were carried out using the FEI 235 DB focused ion beam system, equipped with the EDAX energy dispersive spectrometer (EDS).

The phase analysis was performed by X-ray powder diffraction (XRPD) technique. XRPD patterns were obtained on a PHILIPS PW 1710 diffractometer using monochromatized $\mathrm{CuK} \alpha$ radiation $\left(\lambda=1.54178 \AA\right.$ ) and step-scan mode ( $2 \theta$ range was from 4 to $90^{\circ} 2 \theta$, step $0.02^{\circ} 2 \theta$, time $0.8 \mathrm{~s}$ ).

The thermal behaviour was studied by simultaneous TG-DTA (Setsys, SETARAM Instrumentation, Caluire, France) in the temperature range from 30 to $900{ }^{\circ} \mathrm{C}$. The samples were placed in an $\mathrm{Al}_{2} \mathrm{O}_{3}$ pans and heated at a constant heating rate of $15^{\circ} \mathrm{C} \mathrm{min}-1$ under an air flow $\left(20 \mathrm{~cm}^{3} \mathrm{~min}^{-1}\right)$. Shrinkage data were collected on thermo-mechanical analyzer (TMA, Setsys, SETARAM Instrumentation, Caluire, France) in the same experimental conditions used for TG-DTA study.

\section{Results and discussion}

The results have shown that compressive strength of FA-based geopolymers can be improved by increasing the EAFS amount up to $30 \%$ (Fig. 1(a)). This is attributed to the increase of $\mathrm{CaO}$ content in the initial solid mixture, which is known to improve the strength of GB [3]. The inclusion of $\mathrm{CaO}$ in a geopolymer mixture by the incorporation of slag, introduces soluble $\mathrm{Ca}^{2+}$ ions, which favour the formation of C-A-S-H gel in addition to geopolymer $\mathrm{N}-\mathrm{A}-\mathrm{S}-\mathrm{H}$ gel, which leads to the increase in strength of the geopolymer structure [6,7]. In blended fly ash/slag geopolymeric systems, C-A-S-H precipitates act as nucleation sites and promote rapid geopolymerization [8-10] and the formation of a higher amount of the reaction product which occupy pore space and thus lead to the higher strength of GB $[3,11]$. The sample with the highest strength was the one comprised of $30 \%$ FA and 70\%EAFS i.e. the sample labeled as F/S-70/30. The sample with the EAFS content above $30 \%$ exhibited strength decrease.

The strength change with the EAFS addition correlates well with the change of porosity of $\mathrm{F} / \mathrm{S}$ samples. The values of total pore volume of $\mathrm{F} / \mathrm{S}$ samples with the slag contents of $0,20 \%, 30 \%$ and
$40 \%$ of EAFSS were $0.154 ; 0.142 ; 0.135$ and 0.149 , respectively. The continual pore volume decrease with the slag addition up to $30 \%$ is in agreement with the strength increase of $\mathrm{F} / \mathrm{S}$ samples. However, the EAFS addition in amounts of $20 \%$ and $30 \%$ has no influence on the pore size. In Fig. 1(b) peaks show that the majority of the pores are about $18 \mathrm{~nm}$ in width for samples F/S-100/0, F/S-80/20 and F/ $\mathrm{S}-70 / 30$. The EAFS addition in amounts above $30 \%$ shifts the pore size peak to a higher value $(23 \mathrm{~nm})$ and induces the increase of total pore volume which is sccompained by the strength decrease of GB, probably due to the excess of water in the starting mixture which was not consumed during the geopolymerization process.

The normal consistency of F/S-100/0, F/S-80/20, F/S-70/30 and F/S-60/40 GB pastes were $43.0 \%, 41.5 \%, 40.0 \%$ and $36.0 \%$, respectively. These findings indicate that EAFS addition, in amounts of $20 \%$ and $30 \%$, to the fly ash leads to the slight decrease of water demand for a standard consistency of GB paste. The highest decrease of normal consistency was observed in a mixture with $40 \%$ of slag, which indicates the lowest water demand. The FA is characterized by higher pore volumes and surface areas than EAFS and more liquid was adsorbed on the FA pores than in EAFS during the dissolution process. Thus, with the EAFS replacement for FA, the decrease of the amount of porous FA in FA/EAFS blends is observed, which reduces the water demand for geopolymerization process. Given that the same amount of alkali activator was used in all GB samples it is most likely that, when the EAFS content was above $30 \%$, the excess of water, which was not consumed during the hydration process, caused the increase of porosity and the decrease in strength of GB.

Since the F/S-70/30 sample displayed the highest strength, it was selected for the investigation of thermal resistance of blended FA/EAFS binder. The results presented in Table 1 have shown that EAFS addition has no significant influence on the thermal resistance of FA-based GB during the heating up to $600{ }^{\circ} \mathrm{C}$ although above this temperature, EAFS addition negatively affects thermal resistance of GB.

The microstructure of F/S-70/30 sample (Fig. 2(a)) before heating is characterized by the presence of unreacted FA and EAFS (A) embedded in the reaction product of geopolymerization of the FA/EAFS blend (B). The results of EDS analysis of the reaction product (Fig. 2(b)) indicate the formation of $\mathrm{N}-(\mathrm{C})-\mathrm{A}-\mathrm{S}-\mathrm{H}$ gel with a low Ca content along with geopolymer-type gel (N-A-S-H), as observed previously [12]. Heating up to $600^{\circ} \mathrm{C}$ has no significant influence on the microstructure of the blended FA/EAFS binder (Fig. 2(c) and (d)). After heating to $800{ }^{\circ} \mathrm{C}$ (Fig. 2(e)) the development of a highly porous structure was observed which was accompanied by a high strength loss as shown by the mechanical investigation (Fig. 2(e)).
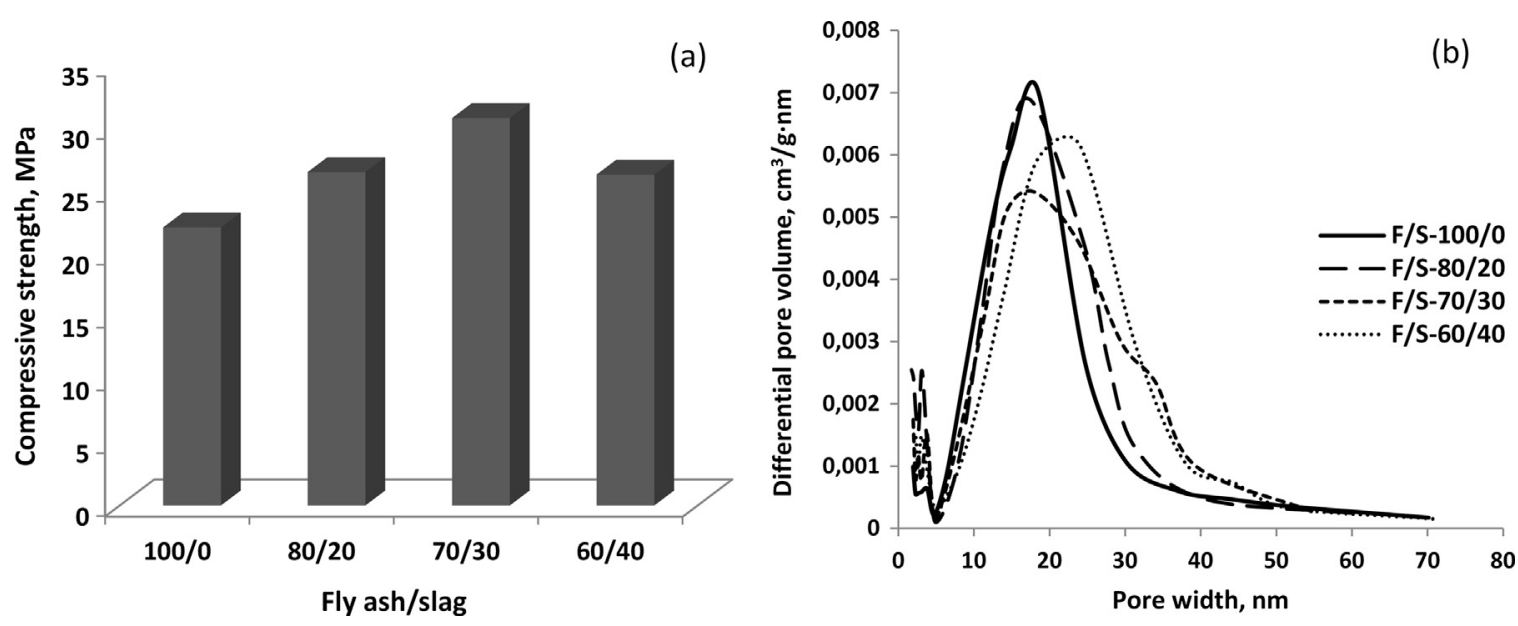

Fig. 1. Compressive strength (a) and pore size distribution (b) of F/S binders with different FA/EAFS. 
Table 1

Compressive strength loss of GB after thermal treatment.

\begin{tabular}{lll}
\hline \multirow{2}{*}{ Temperature $\left({ }^{\circ} \mathrm{C}\right)$} & \multicolumn{2}{l}{ Strength loss $(\%)$} \\
\cline { 2 - 3 } & F/S-100/0 & F/S-70/30 \\
\hline 400 & 34.5 & 32.9 \\
600 & 49.2 & 51.8 \\
800 & 67.0 & 80.2 \\
\hline
\end{tabular}

Fig. 3(a) shows the XRPD patterns of FA, EAFS and F/S-70/30 before and after heating at different temperatures. The XRPD pattern of FA shows the presence of a non-crystallized, i.e., amorphous phase as a main phase. The dominant crystalline phases were identified as quartz, $\mathrm{SiO}_{2}$, and calcite, $\mathrm{CaCO}_{3}$, which are present in very small quantities. The major crystalline peaks in EAFS correspond to wüstite, $\mathrm{Fe}_{1-\mathrm{x}} \mathrm{O}$, larnite, $\beta-\mathrm{Ca}_{2} \mathrm{SiO}_{4}$, gehlenite, $\mathrm{Ca}_{2} \mathrm{Al}\left(\mathrm{AlSiO}_{7}\right)$ and monticellite, $\mathrm{CaMgSiO}$. The XRPD pattern of the $\mathrm{F} / \mathrm{S}-70 / 30$ geopolymer before heating indicates the presence of undissolved ingredients, quartz, calcite and wüstite, leftover from unreacted FA and EAFS. The results show that the F/S binder, after heating up to $600^{\circ} \mathrm{C}$, appeared to be amorphous. Although small amounts of gehlenite, magnetite and/or hematite, formed at lower temperatures, can be observed, the onset of bulk crystallization is at $800{ }^{\circ} \mathrm{C}$. The main crystalline phase identified after heating at the $800{ }^{\circ} \mathrm{C}$ is gehlenite which indicate almost completely decomposition of reaction product of geopolymerization. Hematite, $\alpha-\mathrm{Fe}_{2} \mathrm{O}_{3}$, and magnetite, $\mathrm{Fe}_{3} \mathrm{O}_{4}$, were also found in the XRPD pattern at $800{ }^{\circ} \mathrm{C}$ due to the crystallization from the amorphous iron in the FA [13].

The results of thermal analysis (Fig. 3(b)) indicate sharp initial mass drops on the TG curves and an endothermic peak on the DTA curves during heating up to $200{ }^{\circ} \mathrm{C}$ for both, $\mathrm{F} / \mathrm{S}-70 / 30$ and $\mathrm{F} / \mathrm{S}$ $100 / 0$. Moreover, both samples displayed low temperature shrinkage (Fig. 3(c)) of about $2 \%$ at $200{ }^{\circ} \mathrm{C}$. Observed changes are attributed to the loss of physical bonded water of N-A-S-H and N(C)-A-S-H gels [14,15]. Continual mass loss between 200 and $600{ }^{\circ} \mathrm{C}$ is attributed to the dehydroxylation process of the gel phase $[16,17]$ which has no significant influence on the dimensional stability of the samples. Above $600{ }^{\circ} \mathrm{C}$ mass remained almost at a constant value.

The DTA curves indicate an exothermic peak around $400{ }^{\circ} \mathrm{C}$ which is attributed to oxidation and combustion of unburnt coal trapped inside the remaining fly ash particles [18]. The peak for the $\mathrm{F} / \mathrm{S}-70 / 30$ sample is lower compared to $\mathrm{F} / \mathrm{S}-100 / 0$ because of the lower content of FA in the starting mixture. With further heating, above $500{ }^{\circ} \mathrm{C}$, there were no significant effects on the DTA curve for the $\mathrm{F} / \mathrm{S}-100 / 0$ sample. An additional broad exothermic peak between 500 and $700{ }^{\circ} \mathrm{C}$ was registered at the DTA curve for the F/S-70/30 sample, caused by crystallization effects observed by XRPD analysis. Structural changes of reaction products at high temperatures are accompanied by the high temperature shrinkage, above $600{ }^{\circ} \mathrm{C}$ (Fig. 3(c)) which is reflected in a deterioration of mechanical properties of GB. It is evident that EAFS replacement for the FA negatively affects the dimensional stability of GB above $600{ }^{\circ} \mathrm{C}$ because it shifts the onset of high temperature shrinkage to lower temperatures.

The strength decrease and shrinkage of GB samples after exposure to temperatures up to $600{ }^{\circ} \mathrm{C}$ is a result of structure damage (cracks) caused by the dehydration process [19]. Evaporation of water during heating produces pressure which, in a dense matrix with less permeability, causes thermal cracks due to thermal shrinkage [14]. The viscous sintering of aluminosilicate phases from gel and unreacted fly ash occurs near $600{ }^{\circ} \mathrm{C}$. The sintering effect mainly induces strength gain of GB due to the densification of GB structure and improved inter particle connectivity [20-22]. It is proposed that sintering causes localized strength increas, whereas bulk cracking results in general strength loss [19]. It is likely that that strength reducing effects such as dehydration and rapid crystallization above $600{ }^{\circ} \mathrm{C}$ were more dominant in GB
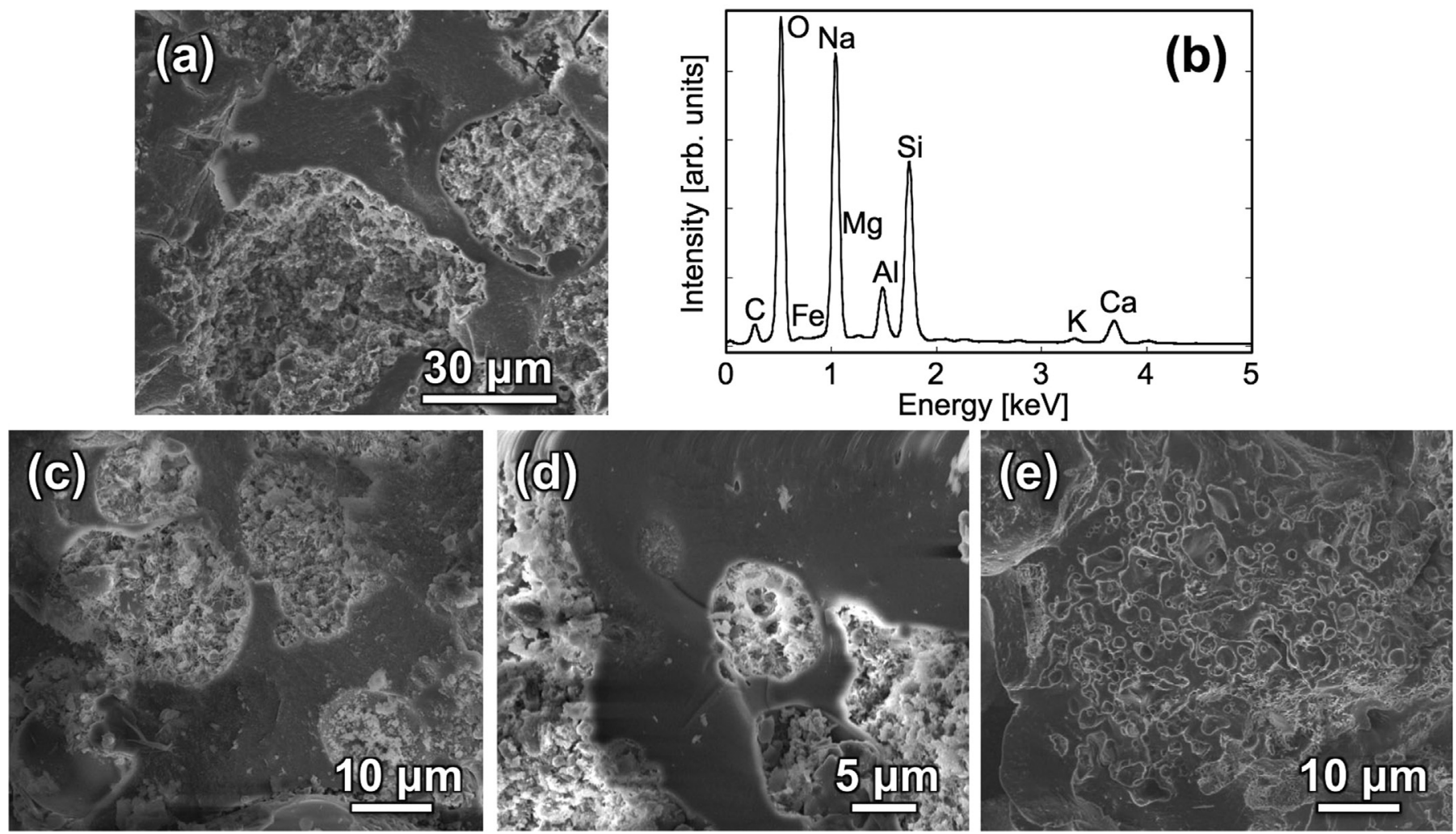

Fig. 2. SEM/EDS of blended FA/EAFS binder before (a, b) and after exposure to the (c) $400{ }^{\circ} \mathrm{C}$, (d) $600{ }^{\circ} \mathrm{C}$ and (e) $800{ }^{\circ} \mathrm{C}$. 
(a)
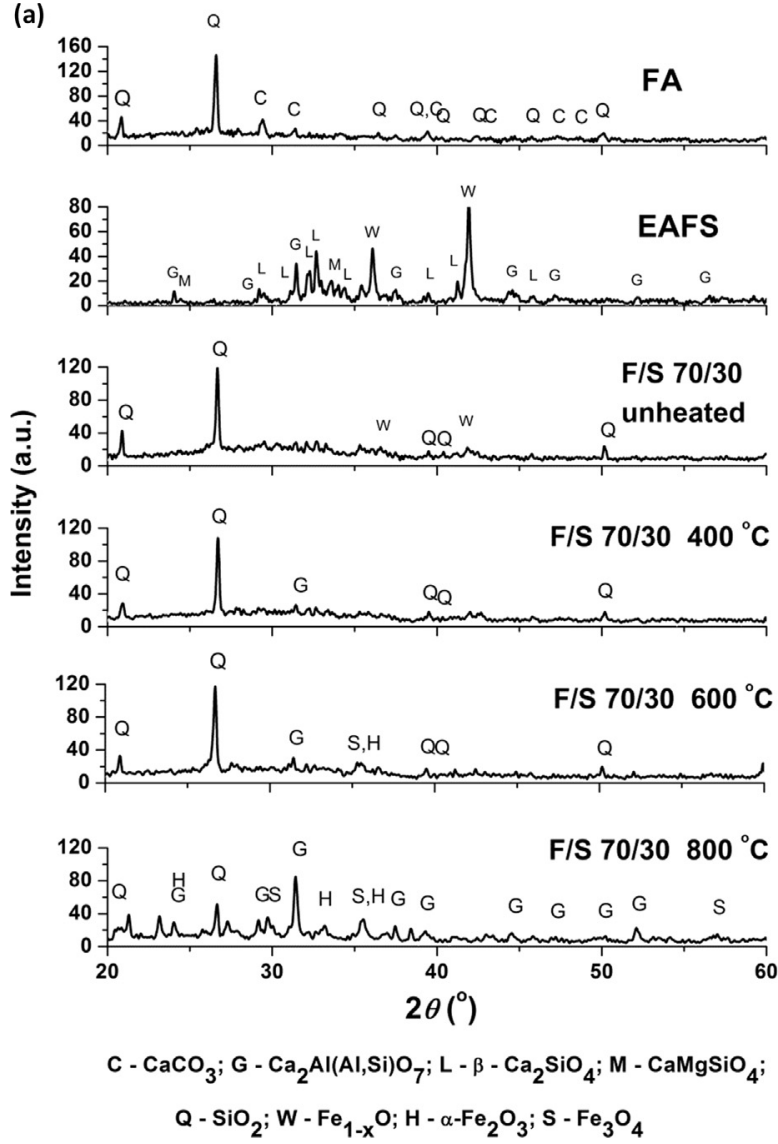

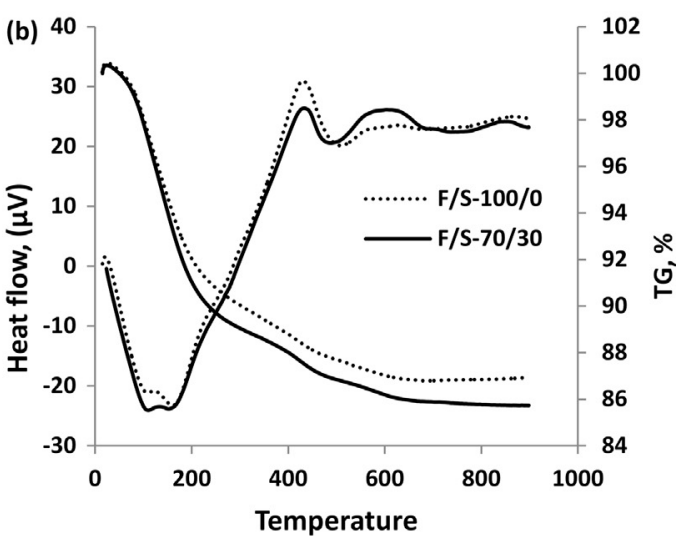

(c)

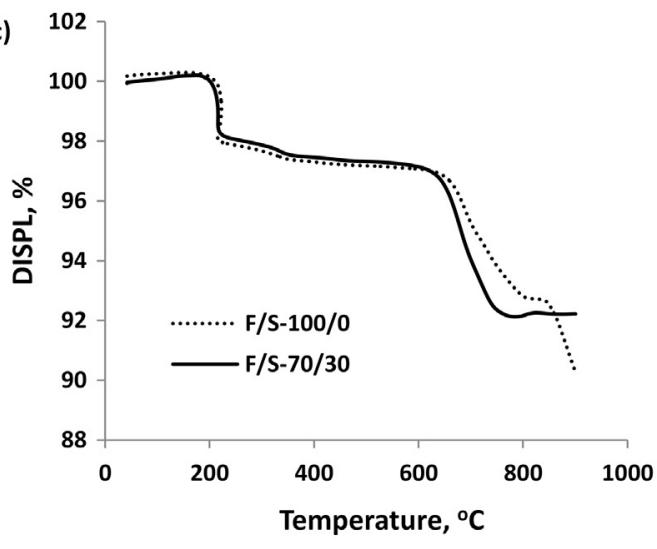

Fig. 3. XRD patterns of FA, EAFS and F/S-70/30 samples before and after heating (a); TG-DTA thermograms (b) and shrinkage (c) of F/S-100/0 and F/S-70/30 samples.

samples investigated in this study than the strength improving effects such as sintering, which is reflected in continual strength loss of GB upon heating.

\section{Conclusions}

The EAFS replacement of FA in the amounts up to 30\% improves the strength of FA-based GB. The EAFS addition causes large loss in strength, after heating above $600{ }^{\circ} \mathrm{C}$, due to the structural changes of the amorphous gel phase. Geopolymers (F/S-70/30) remained amorphous when heated up to $600{ }^{\circ} \mathrm{C}$ while crystallization was observed at $800{ }^{\circ} \mathrm{C}$. We found gehlenite as the dominant crystalline phase formed in $\mathrm{F} / \mathrm{S}-70 / 30$ sample after heating to $800{ }^{\circ} \mathrm{C}$. High temperature shrinkage of GB which contain 30\% EAFS was higher and also occurs at lower temperatures than that of purely FA based GB.

\section{Acknowledgements}

The authors would like to acknowledge financial support of the Montenegrin Ministry of Science in the framework of project no. 01-460, and from the Ministry of Education, Science and Technological Development of the Republic of Serbia for the projects: No. III45007, No. III45019, and No. 172054. V. R. R also acknowledges support from Serbian Academy of Sciences and Arts, under the project No. F-141.

\section{References}

[1] A. Fernández-Jiménez, A. Palomo, Composition and microstructure of alkali activated fly ash binder: Effect of the activator, Cem. Concr. Res. 35 (2005) 1984-1992, http://dx.doi.org/10.1016/j.cemconres.2005.03.003.

[2] I. Nikolić, L. Karanović, I.J. Častvan, V. Radmilović, S. Mentus, V. Radmilović, Improved compressive strength of alkali activated slag upon heating, Mater. Lett. 133 (2014) 251-254, http://dx.doi.org/10.1016/j.matlet.2014.07.021.

[3] S. Kumar, R. Kumar, S.P. Mehrotra, Influence of granulated blast furnace slag on the reaction, structure and properties of fly ash based geopolymer, J. Mater. Sci. 45 (2010) 607-615, http://dx.doi.org/10.1007/s10853-009-3934-5.

[4] H.K.L.H. Lee, Reactivity and reaction products of alkali-activated, fly ash/slag paste, Constr. Build. Mater. 81 (2015) 303-312.

[5] N. Marjanović, M. Komljenović, Z. Baščarević, V. Nikolić, R. Petrović, Physicalmechanical and microstructural properties of alkali-activated fly ash-blast furnace slag blends, Ceram. Int. 41 (2015) 1421-1435, http://dx.doi.org/ 10.1016/j.ceramint.2014.09.075.

[6] A. Buchwald, R. Tatarin, D. Stephan, Reaction progress of alkaline-activated metakaolin-ground granulated blast furnace slag blends, J. Mater. Sci. 44 (2009) 5609-5617, http://dx.doi.org/10.1007/s10853-009-3790-3.

[7] S.K. Nath, S. Kumar, Influence of iron making slags on strength and microstructure of fly ash geopolymer, Constr. Build. Mater. 38 (2013) 924-930, http: //dx.doi.org/10.1016/j.conbuildmat.2012.09.070.

[8] C.K. Yip, G.C. Lukey, J.L. Provis, J.S.J. van Deventer, Effect of calcium silicate sources on geopolymerisation, Cem. Concr. Res. 38 (2008) 554-564, http://dx. doi.org/10.1016/j.cemconres.2007.11.001.

[9] S. Puligilla, P. Mondal, Role of slag in microstructural development and hardening of fly ash-slag geopolymer, Cem. Concr. Res. 43 (2013) 70-80, http: //dx.doi.org/10.1016/j.cemconres.2012.10.004.

[10] J. Temuujin, A. van Riessen, R. Williams, Influence of calcium compounds on the mechanical properties of fly ash geopolymer pastes, J. Hazard. Mater. 167 (2009) 82-88, http://dx.doi.org/10.1016/j.jhazmat.2008.12.121.

11] K. Dombrowski, A. Buchwald, M. Weil, The influence of calcium content on the structure and thermal performance of fly ash based geopolymers, J. Mater. Sci. 42 (2007) 3033-3043, http://dx.doi.org/10.1007/s10853-006-0532-7.

[12] I. Ismail, S.A. Bernal, J.L. Provis, R. San Nicolas, S. Hamdan, J.S.J. van Deventer, Modification of phase evolution in alkali-activated blast furnace slag by the incorporation of fly ash, Cem. Concr. Compos. 45 (2014) 125-135, http://dx.doi. org/10.1016/j.cemconcomp.2013.09.006.

[13] W.D. a Rickard, A. Van Riessen, P. Walls, Thermal character of geopolymers synthesized from class F Fly ash containing high concentrations of iron and a-Quartz, Int. J. Appl. Ceram. Technol. 7 (2010) 81-88, http://dx.doi.org/ 10.1111/j.1744-7402.2008.02328x.

[14] O.A. Abdulkareem, A.M. Mustafa Al Bakri, H. Kamarudin, I. Khairul Nizar, A. 
a Saif, Effects of elevated temperatures on the thermal behavior and mechanical performance of fly ash geopolymer paste, mortar and lightweight concrete, Constr. Build. Mater. 50 (2014) 377-387, http://dx.doi.org/10.1016/j. conbuildmat.2013.09.047.

[15] W. Chen, H.J.H. Brouwers, The hydration of slag, part 1: reaction models for alkali-activated slag, J. Mater. Sci. 42 (2007) 428-443, http://dx.doi.org/ $10.1007 /$ s10853-006-0873-2.

[16] E. Ul Haq, S.K. Padmanabhan, A. Licciulli, In-situ carbonation of alkali activated fly ash geopolymer, Constr. Build. Mater. 66 (2014) 781-786, http://dx.doi.org/ 10.1016/j.conbuildmat.2014.06.012.

[17] S.A. Bernal, J.L. Provis, B. Walkley, R. San Nicolas, J.D. Gehman, D.G. Brice, et al., Gel nanostructure in alkali-activated binders based on slag and fly ash, and effects of accelerated carbonation, Cem. Concr. Res. 53 (2013) 127-144, http: //dx.doi.org/10.1016/j.cemconres.2013.06.007.

[18] E. Ul Haq, S. Kunjalukkal Padmanabhan, A. Licciulli, Synthesis and characteristics of fly ash and bottom ash based geopolymers-A comparative study, Ceram. Int. 40 (2014) 2965-2971, http://dx.doi.org/10.1016/j. ceramint.2013.10.012.

[19] W.D.A. Rickard, C.S. Kealley, A. Van Riessen, Thermally induced microstructural changes in fly ash geopolymers: Experimental results and proposed model, J. Am. Ceram. Soc. 98 (2015) 929-939, http://dx.doi.org/10.1111/ jace.13370.

[20] W.D.A. Rickard, J. Temuujin, A. Van Riessen, Thermal analysis of geopolymer pastes synthesised from five fly ashes of variable composition, J. Non. Cryst. Solids 358 (2012) 1830-1839, http://dx.doi.org/10.1016/j. jnoncrysol.2012.05.032.

[21] A. Fernández-Jiménez, A. Palomo, J.Y. Pastor, A. Martin, New cementitious materials based on alkali-activated fly ash : performance at high temperatures, J. Am. Ceram. Soc. 91 (2008) 3308-3314, http://dx.doi.org/10.1111/j.15512916.2008.02625.x.

[22] W.D.A. Rickard, R. Williams, J. Temuujin, A. van Riessen, Assessing the suitability of three Australian fly ashes as an aluminosilicate source for geopolymers in high temperature applications, Mater. Sci. Eng. A. 528 (2011) 3390-3397, http://dx.doi.org/10.1016/j.msea.2011.01.005. 